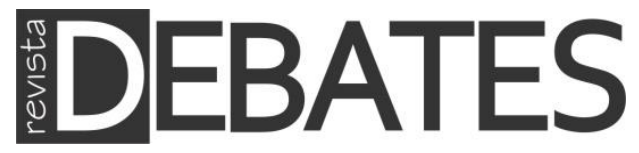

\title{
Golpe de Estado y Neogolpismo en América Latina
}

Coup d'état and neo coup d'état in Latin America

\section{Octavio Humberto Moreno Velador Carlos Alberto Figueroa Ibarra}

\section{Resumen}

En este artículo se presenta un análisis comparativo entre los Golpes de Estado (GE) que se presentaron durante el siglo XX en América Latina y sus nuevas modalidades en el siglo XXI. Con base en la revisión conceptual y el análisis de casos se plantea una discusión acerca de la definición del Golpe de Estado, además de una caracterización de los nuevos golpes de Estado o Neogolpismo.

\section{Palabras clave}

Golpe de Estado; Neogolpismo; Democracia; Violencia; Latinoamérica.

\section{Abstract}

This article presents a comparative perspective between the coup d'état on the XX century and its new modalities on the XXI century on Latin America. Based on a conceptual revision and analysis of cases, we discuss the conceptualization of coup d'état, beside a characterization of the contemporary coup d'état or neo coup d'état.

\section{Keywords}

Coup d'État; Neo Coup d'État; Democracy; Violence; Latin America. 


\section{Introducción ${ }^{1}$}

Un paradigma que orientó buena parte del trabajo de la ciencia política y la Sociología Política durante los últimos veinte años en América Latina fue el de la democratización y la consolidación democrática en la región. Fue gracias a los procesos de transición iniciados en los años ochenta del siglo $\mathrm{XX}$, que la democracia se volvió un tema central durante un espacio de más de veinte años (O’DONNELL, SCHMITER y WHITEHEAD, 1994; MORLINO, 2005). Para buena parte de los estudiosos de la política y la sociología de la región, parecía que en adelante todas las discusiones acerca del Estado y de la política nacional o internacional tendrían como premisa la existencia de la democracia, ya fuera de alta o baja calidad, consolidada o no, o con uno u otro adjetivo (LYNN, 1990; GARRETÓN, 1997; SMITH, 2004 y 2009; PÉREZ-LIÑÁN y WHITEHEAD, 2011; GARGARELLA, 2015 y 2017).

Sin embargo, los primeros 17 años del siglo XXI han traído de vuelta un fenómeno que se pensaba superado, esto el surgimiento de nuevos Golpes de Estado (GE) en casos como los de Venezuela (2002), Haití (2004), Bolivia (2008), Honduras (2009), Ecuador (2010), Paraguay (2012) y Brasil (2016). Desde nuestra perspectiva el resurgimiento del GE implica un cuestionamiento de fondo a todos los esfuerzos políticos por construir democracia en la región, así como también a todos aquellos modelos teóricos que han intentado de una $\mathrm{u}$ otra forma influir en su construcción. Principalmente de aquellas ópticas que centraron en su parte meramente procedimental (PRZEWORSKI, 2010; ANSALDI, 2001 y 2008).

Los nuevos Golpes de Estado, o Neogolpismo, varían sensiblemente de acuerdo al tipo clásico de GE que se presentó durante el siglo $\mathrm{XX}$, ya que poseen características novedosas que hacen de su investigación un asunto importante para mantener el orden democrático e institucional en los países de la región. Por ello presentamos en este artículo una revisión conceptual del GE, para después contrastar este concepto con las tendencias que tuvo el fenómeno durante el siglo XX. Posteriormente presentamos una revisión y análisis de ocho casos recientes en la

\footnotetext{
${ }^{1}$ Este trabajo es posible gracias al grupo de trabajo "Neogolpismo en América Latina” que se formó con estudiantes de la Facultad de Derecho y Ciencias Sociales de la Benemérita Universidad Autónoma de Puebla, gracias a ellos fue posible la recopilación de la mayor parte de los datos históricos que alimentan esta investigación: Sebastián Arroy Juárez, Samantha Dorelí Álvarez Jiménez, Alexander Bermejo Aguilar, Sara Adriana Reyes Cortés, Héctor Manuel Polaco Romero, Esliyarency Gaona Cabrera, Diana Úrsula Pérez Guevara, Irani Estephany Santamaría Castro, Mónica Michelle Santos Iturbide y Cristopher Mejía Rosas.
} 
región a fin de poder captar sus principales tendencias y posibles características. A partir de ello presentamos una propuesta conceptual para definir al neogolpismo y contrastarlo conceptualmente con el GE en su acepción clásica. Finalmente presentamos una serie de conclusiones tentativas que permita comprender la importancia de este fenómeno y los riesgos que implica en la política regional.

\section{La definición del Golpe de Estado}

Existe un consenso en las diferentes conceptualizaciones acerca de las principales características del GE. En principio se trata de un acto llevado a cabo para deponer un gobernante o gobierno determinado y colocar a otro en su lugar, incluyendo la posibilidad de que el golpe se genere por el propio gobernante para reforzar su poder o bien de algún sector dentro del poder instaurado (BARBÉ, 2015; SERRA, 1998; NOHLEN, 2006; RAMÍREZ y RAMÍREZ, 1997; POLITICUS, 2001). En este sentido, si bien hablar de GE implica hablar de Estado, la deposición llevada a cabo es en realidad de un gobierno y no de un Estado. En este sentido es más conveniente entender al Estado como una construcción más amplia que un gobierno, que incluye tanto dominación como consenso, y que se vale del orden institucional para poder construirse y mantenerse. Desde esta perspectiva, el Estado en su construcción institucional y la definición del interés general, se muestra como producto de la compleja correlación de fuerzas que se teje entre los diferentes grupos y corrientes políticas, económicas y sociales que se presentan en un Estado-nación determinado (a veces incluyendo incluso el entorno internacional), y va más allá del propio gobierno. Visto de esta manera es posible entender cómo una fuerza política que no ocupa el poder de gobierno, busca deponer a otra fuerza para ocupar esa posición y además puede poseer la suficiente fuerza para deponer a él o los gobernantes instaurados (GRAMSCI, 1999; LECHNER, 1977; PORTANTIERO, 1981; OLIVER, 2009).

Por otro lado, se puede distinguir al GE de un fenómeno como el de la Revolución, ya que el GE es impulsado desde el interior del aparato gubernamental por personas o grupos que buscan reforzar su poder dentro de dicho aparato y no es un fenómeno que provenga desde abajo, es decir, usualmente no tiene participación de los grupos populares, aun habiendo la posibilidad de que existan protestas y movilizaciones sociales antes o después del acto (BARBÉ, 2015; SERRA, 1998; NOHLEN, 2006). Por otro lado, el GE no aspira a crear una situación de transformación en el status quo de una sociedad determinada, como sí se plantea en los fenómenos revolucionarios, esto es "de derribar a las autoridades políticas 
existentes y de sustituirlas con el fin de efectuar profundos cambios en las relaciones políticas, en el ordenamiento jurídico institucional y en la esfera socioeconómica" (PASQUINO, 1982, p. 1458).

Otro elemento característico del GE es la necesaria violación del orden legal e institucional para generar el cambio de poder, proviniendo de sectores o grupos colocados dentro de la propia organización gubernamental con el objetivo de apropiarse de los órganos del poder político. Dichos sectores o grupos aspiran a cambiar el orden jurídico a favor de los actores del golpe, a fin de imponer "su propia legalidad" (BARBÉ, 2015, p. 723; NOHLEN, 2006).

Un GE puede ser organizado y protagonizado por un "grupo o sector oficial, de carácter civil, militar o combinado” (BARBÉ, 2015, p. 723), los actores implicados pueden provenir tanto del ejército como de órganos como el parlamento $\mathrm{u}$ otras posiciones gubernamentales. Sin embargo, para la literatura especializada basada en las experiencias del siglo XX, un actor central suelen ser los jefes militares ya que debido a su control de las armas resultan decisivos en el desarrollo de un GE, ya fuera por su acción, neutralidad o complicidad (ROUQUIÉ, 1984 y 2011). En este sentido, el GE en América Latina se encuentra fuertemente ligado con las institucionales militares y su captura del Estado tanto en un sentido material como simbólico

\begin{abstract}
Material, en la medida en que fueron golpes que utilizaron la infraestructura propia de una situación de guerra, movilizando sofisticados recursos para la conquista efectiva de instituciones organizadas exclusivamente desde el poder civil. Simbólico, debido a que dichas instituciones no sólo representaban los puntos más significativos del campo político (llámese casa de gobierno, ministerios, medios de comunicación, universidades), sino que, además, sobre ellas se desplegó un conjunto de códigos altamente jerarquizados destinados a invadir el ámbito público de un principio de excepcionalidad, hasta entonces, propio de situaciones catastróficas o de agresión externa (VICTORIANO, 2014, p. 176).
\end{abstract}

Finalmente tenemos que la violencia puede hacerse presente como parte de la realización del GE, aunque no necesariamente en todos los casos.

Este conjunto de elementos da una conceptualización clara del GE que se condice con las principales tendencias que presentó este fenómeno en América Latina durante el siglo XX. A este respecto los datos históricos recabados en este trabajo 
muestran una clara tendencia acorde con las características consideradas en todas las conceptualizadas consideradas.

\section{Tendencias del Golpe de Estado en América Latina durante el siglo XX}

Se recabó información de diversas fuentes especializadas hasta registrar un total de 87 casos de GE exitosos en la región de América del Sur y el Caribe durante el siglo XX. ${ }^{2}$ La distribución de todos los casos varía entre los diferentes estados, aunque el país con más registros es Bolivia con 12, le siguen Chile y Argentina con 6, Guatemala y El Salvador con 5, y los casos con menos registros son Cuba y Costa Rica con 2, y México y Surinam con 1 (Ver Gráfico 1).

Gráfica 1 - Número de GE por país 1900-1999

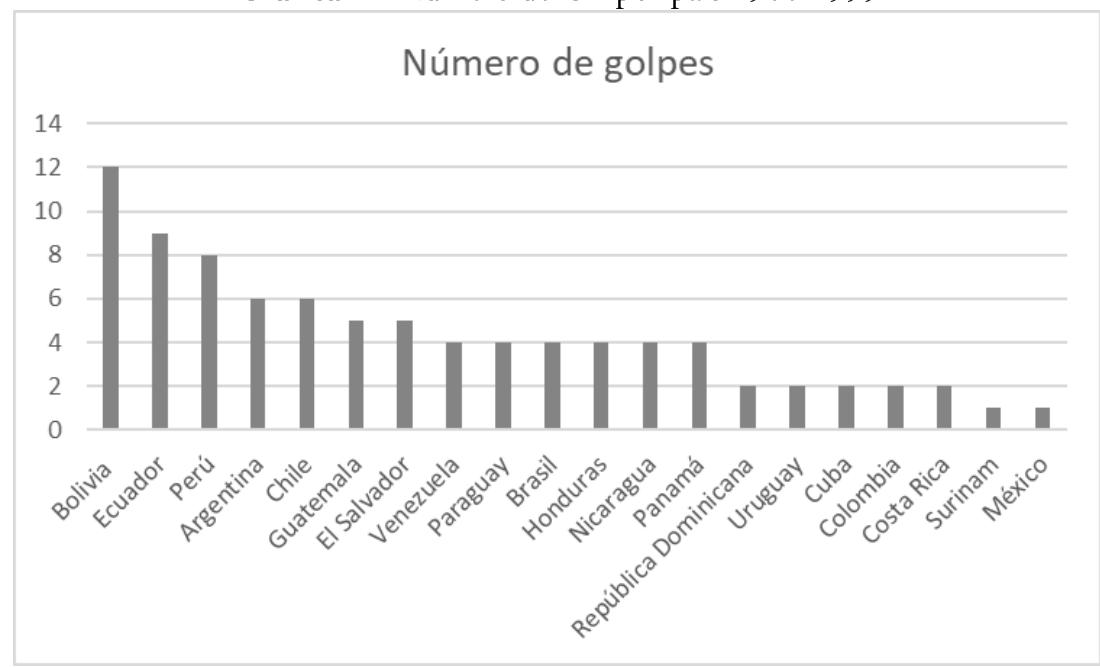

Fuente: Elaborada con datos propios.

\footnotetext{
${ }^{2}$ El grupo de investigación recabó de diversos documentos especializados información sobre casos de GE por cada caso nacional en la región durante el siglo XX (1901-2000). La recopilación consideró casos reconocidos como exitosos, sin considerar asonadas, pronunciamiento, levantamientos, guerras civiles o revoluciones. Es importante aclarar que la recopilación de casos no aspira a ser absoluta, ya que como parte de los hallazgos de la investigación encontramos que no existe en la literatura histórica un consenso sobre muchos de los casos en la región. Por ejemplo, un autor como Modesto Emilio Guerrero contabiliza, entre 1902 y 2002, 327 casos; sin embargo, su recuento no distingue entre golpes, asonadas, pronunciamientos, levantamientos y guerras civiles (GUERRERO, 2006). Por lo tanto, solo se consideraron para la muestra los casos recurrentemente reconocidos como exitosos.
} 
La distribución temporal de los GE nos indica que en cuatro décadas se han concentrado la mayor cantidad de casos: 1930-1939 con 18 casos, 1940-1949 con 12, 1960-1969 con 16 y 1970-1979 con 13 casos, y en las décadas de 1900-1909 y 1990-1999 se presentan la menor cantidad de casos con 3 y 1 respectivamente (Ver Gráfica 2).

Gráfica 2 - Distribución de casos por décadas

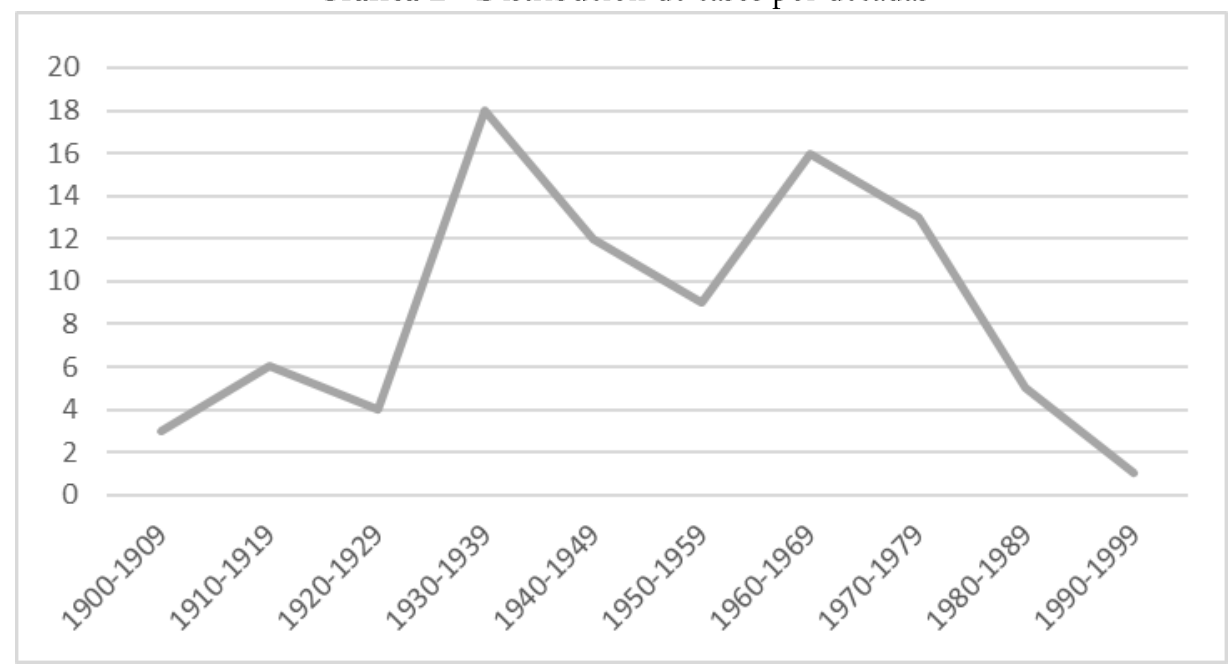

Fuente: Elaborada con datos propios.

En cuanto a la modalidad del GE se elaboró una tipología que distingue primero entre golpes y autogolpes, para después distinguir entre diversas modalidades: militares, civiles, parlamentarios, autogolpes presidenciales, autogolpes militares y autogolpes parlamentarios. De esta forma se encontró que 63 fueron de tipo militares, 7 fueron golpes civiles, 8 fueron golpes de tipo cívico militares, 6 fueron autogolpes de tipo presidenciales y 3 autogolpes militares. No se encontraron casos de golpes o autogolpes de tipo parlamentario (Ver Gráfica 3). 
Gráfica 3 - Cantidad y tipo de GE

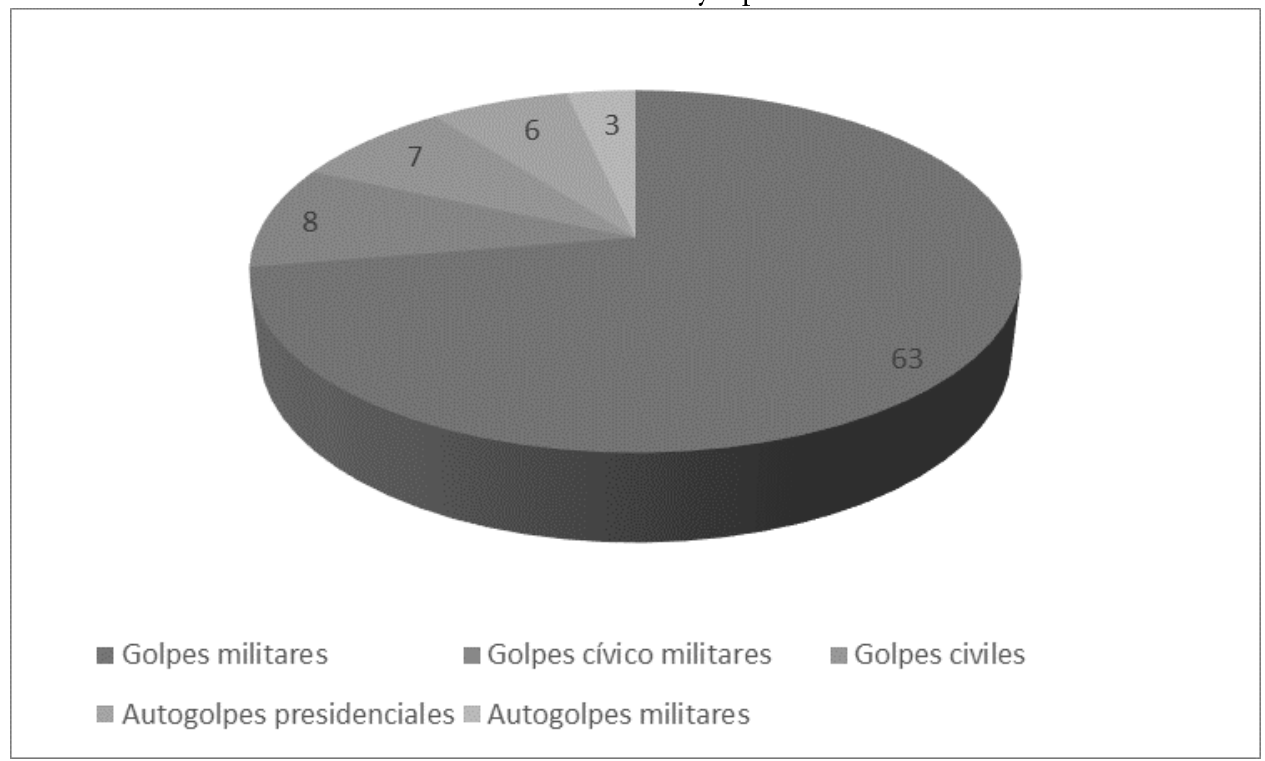

Fuente: Elaborada con datos propios.

En tanto el GE implica la ruptura del orden legal a institucional instaurado, se acompaña usualmente de la instalación de dictaduras que pueden ser breves o prolongadas, de acuerdo a la cantidad de tiempo que se mantienen en el poder o que tardan en llamar a nuevas elecciones para recomponer el orden democrático. A este respecto se propone una distinción entre dictaduras provisionales (que se mantienen en el poder entre un día o hasta tres años) y dictaduras permanentes (que se mantienen desde tres y hasta cinco años o más). El hallazgo a este respecto es que $65,5 \%$ de los GE (57 casos) dieron pie a dictaduras provisionales y $32 \%$ dieron paso a dictaduras permanentes (30 casos). Medido en años, 57 casos la dictadura solamente pasó entre 0 y 3 años en el poder, 8 pasaron entre tres y cinco años y 22 pasaron 5 años o más en el poder (Ver Gráfica 4). 
Gráfica 4 - Duración de años en el poder tras el GE

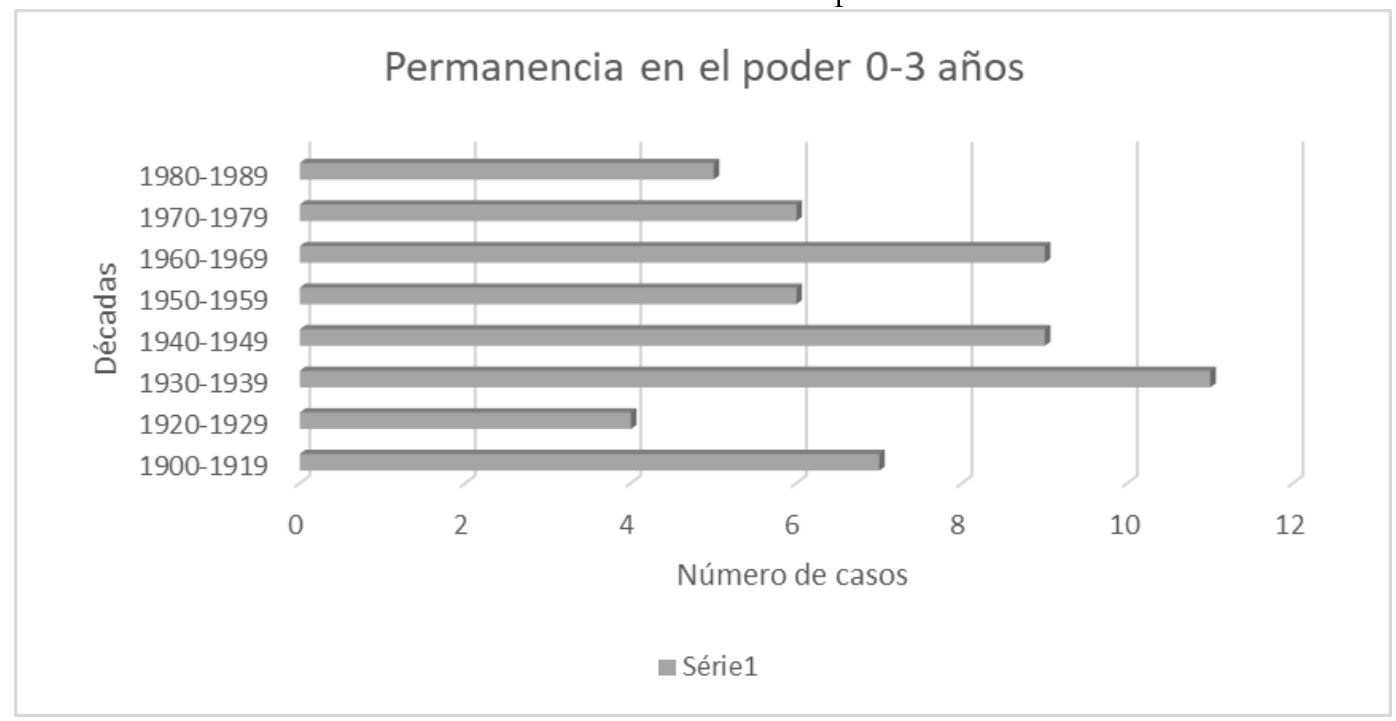

Fuente: Elaborada con datos propios.

Respecto a la forma que tomó el poder tras el GE encontramos dos grandes tipos, la instauración de una dictadura personal de tipo civil o militar, o bien la instauración de una junta de gobierno militar o cívico militar. Los datos obtenidos nos muestran que de 87 casos 12 tomaron la forma de dictadura personal civil, 44 de dictadura militar personal, 17 fueron juntas militares y 14 fueron juntas cívico militares. En términos porcentuales el 64\% fueron dictaduras personales (cívicas o militares) y el $36 \%$ fueron juntas de gobierno (militares o cívico militares) (Gráfica $5)$. 
Gráfica 5 - Tipo de dictadura y número de casos por cada tipo

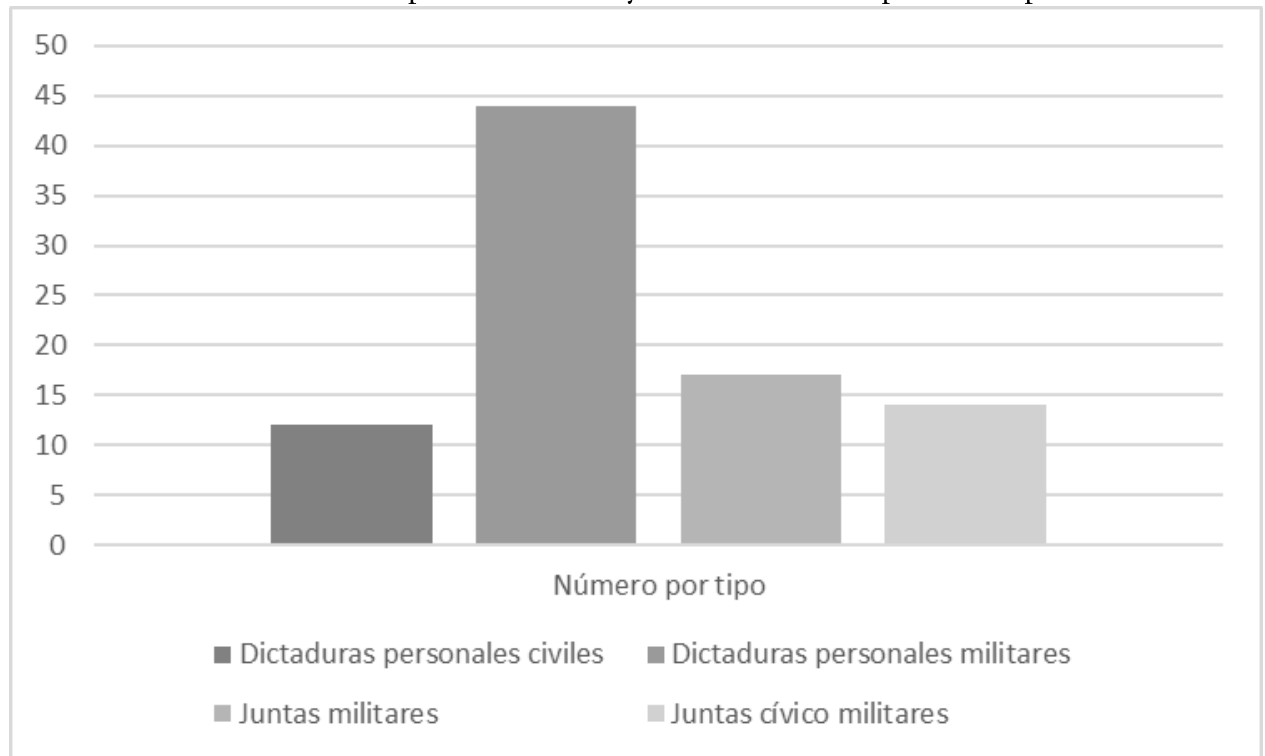

Fuente: Elaborada con datos propios.

Por otro lado, en la realización de un GE cuenta mucho el contexto histórico particular de cada caso, por ello la presencia de protestas y disturbios sociales aparece en muchos casos. En específico encontramos que, de los 87 casos revisados, 29 de ellos presentaron protestas previas al GE y en 16 se presentaron protestas posteriores.

Como parte de la concepción generalizada acerca de los GE se considera que la injerencia extranjera, en particular de los EE.UU., ha resultado central en la realización de numerosos casos. Los datos obtenidos en esta investigación solo mostraron una intervención probada y documentada de los EE.UU. en 24 casos, concentrándose la mayor parte en los años 60 's con 9 casos.

Finalmente, se encontró en $77 \%$ de los casos una marcada influencia de ideología de derecha y participación de partidos de derecha. A diferencia de un 14\% de los casos en los que se encuentra una abierta ideología de izquierda con participación de partidos y fuerzas políticas de izquierda. En el $9 \%$ restante de los casos no se pudo identificar una tendencia política ideológica clara (Gráfica 6). 
Gráfica 6 - Ideología del GE

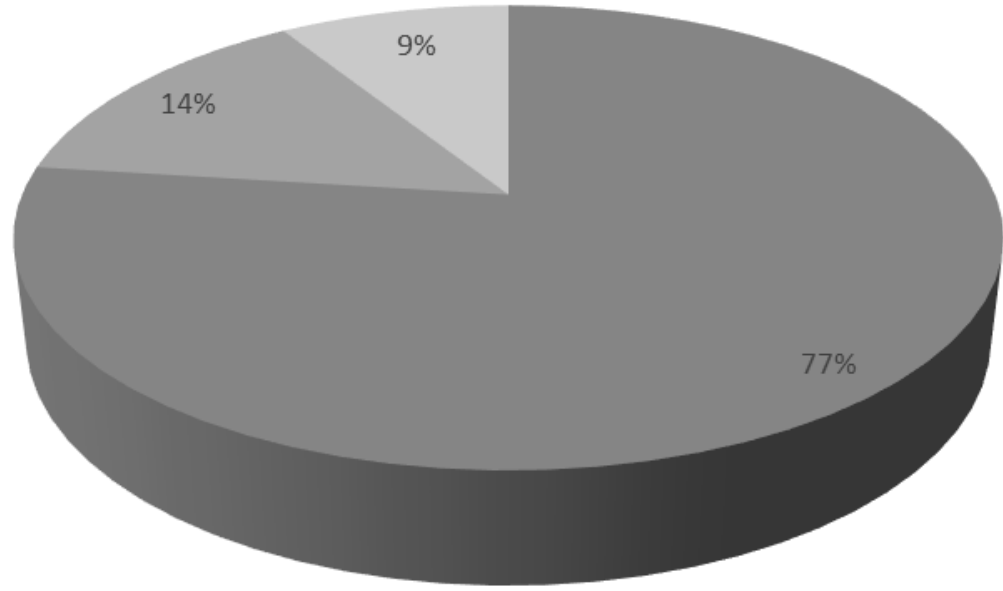

- Derecha $\quad$ Izquierda $\quad$ Indeterminado

Fuente: Elaborada con datos propios.

Los datos aquí señalados permiten entender las principales tendencias del GE en AL durante el siglo XX:

- Durante el siglo XX, el GE fue un fenómeno frecuente en la región;

- Los países que tuvieron mayor cantidad de casos son Bolivia y Ecuador;

- Cuatro décadas en especial tuvieron la mayor cantidad de casos: 30 's, 40's, 60's y 70's;

- El tipo de GE que predominó fue el militar, muy por encima de los civiles, presidenciales, cívico-militares y de los autogolpes;

- Como producto de los GE se instalaron tanto dictaduras personales como juntas que en su mayoría no duraron en el poder más allá de 3 años. Sin embargo, existe un número significativo de dictaduras que se prolongaron más allá de cinco años en el poder;

- La forma de dictadura más común instalada tras el GE fue la dictadura de tipo personal y militar;

- El GE es un fenómeno mucho más relacionado con la ideología y fuerzas políticas de derecha que con las de izquierda. 
Este conjunto de características extraídas del conjunto de casos analizados resulta congruente con la conceptualización que se hizo desde la ciencia política y la sociología política del GE en el siglo XX. Sin embargo, los primeros años del siglo XXI han traído de vuelta este fenómeno, aunque ahora presenta algunas características que lo hacen distinto de la forma típica que ya se ha analizado en este trabajo. Para demostrar lo anterior a continuación analizamos los casos de nuevos GE o Neogolpismo que se han presentado en los últimos diecisiete años en la región y presentamos una discusión acerca de este cambio y la consecuente adaptación conceptual que el fenómeno podría tener.

\section{E1 Golpe de Estado en el siglo XXI}

A partir del año 2001 se han registrado un total de 7 fenómenos de GE en la región, de los cuales solo 4 han resultado exitosos (Tabla 1) $)^{3}$. De forma similar a lo acontecido en el siglo XX, en la totalidad de los fenómenos existe un predominio de partidos e ideología de derecha.

Tabla 1 - Golpes exitosos y fracasados en el S XXI

\begin{tabular}{c|c|c|c}
\hline País & Ańo & Día y mes & Resultado \\
\hline Venezuela & 2002 & 13 de abril & Fracasado \\
\hline Haití & 2004 & 29 de febrero & Exitoso \\
\hline Bolivia & 2008 & 11 septiembre & Fracasado \\
\hline Honduras & 2009 & 28 de junio & Exitoso \\
\hline Ecuador & 2010 & 30 de septiembre & Fracasado \\
\hline Paraguay & 2012 & 22 de junio & Exitoso \\
\hline Brasil & 2016 & 31 de agosto & Exitoso \\
\hline
\end{tabular}

Fuente: Elaborada con datos propios.

En cuanto al tipo de GE tenemos que, considerando tanto exitosos como fracasados, 4 han sido del tipo militar/policial (Venezuela 2002, Haití 2004, Honduras 2009, Ecuador 2010), 2 han sido golpes parlamentarios (Paraguay 2012 y Brasil 2012) y 1 ha sido golpe civil-oficial (Bolivia 2008) (Gráfica 7). A diferencia de lo sucedido en el SXX, en solo dos casos existe evidencia de la intervención de los E.U.; hablamos del caso de Haití en 2004, en donde el secuestro y deportación del presidente fue a manos del ejército norteamericano (ÁLVAREZ, 2010); y el caso de

${ }^{3}$ Para abordar los GE del siglo XXI consideramos tanto golpes fracasados como exitosos debido al limitado universo de estudio, así como a la posibilidad de analizar las características de las intentonas. 
Bolivia en 2008, donde el gobierno de Morales sostuvo que el ex embajador, Philip Goldberg, mantuvo reuniones con el prefecto de Santa Cruz y con uno de los líderes opositores, Rubén Costas ${ }^{4}$.

A partir de estos datos no se puede presentar una tipología pura acerca de los nuevos GE, ya que en tanto la forma militar predominante durante el siglo XX ha ido a la baja, se han entremezclado diferentes variantes del fenómeno que a continuación analizamos.

Gráfica 7 - Tipo de golpe en el siglo XXI

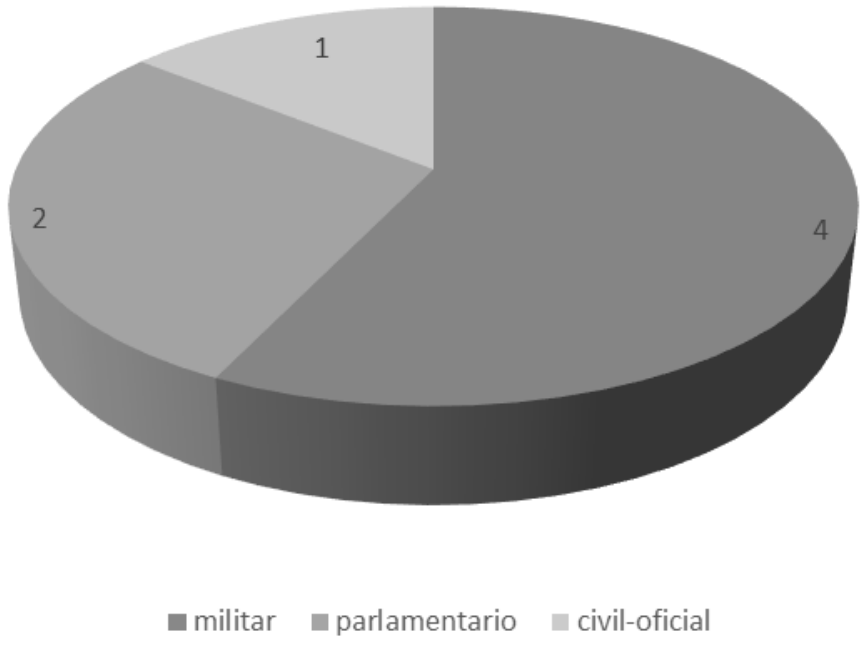

Fuente: Elaborada con datos propios.

a) Participación de las fuerzas armadas

Como dicta su definición conceptual, el GE necesita de la participación directa o al menos la anuencia de las fuerzas armadas para poderse llevar a cabo, sin embargo, a partir del año 2001 sólo en 4 casos han tenido participación directa. En Venezuela 2002, una parte del ejército capturó al presidente y posteriormente en cadena nacional el General Lucas Rincón anunció que Chávez había aceptado firmar su renuncia. Pocas horas después un grupo de militares leales a Chávez lo rescataron del cautiverio (RUÍZ, 2016).

${ }^{4}$ Incluso el gobierno boliviano presentó una protesta formal ante la administración de George W. Bush. 
En el caso de Haití 2004, tras un período de impasse político, el presidente Jean-Bertrande Aristide fue detenido por miembros del ejército estadounidense con complicidad oficial francesa, y deportado a la República Centroafricana (MEYSSAN, 2004; ÁLVAREZ, 2009).

El 28 de junio de 2009, el palacio presidencial de Honduras fue asaltado por fuerzas armadas estadounidenses, quienes detuvieron al presidente Manuel Zelaya y lo obligaron a salir al exilio a Costa Rica. En este caso el ejército había caído previamente en rebeldía cuando se negó a distribuir los materiales electorales necesarios para realizar una "encuesta de opinión pública" para crear una nueva Constitución de la República (AGUILAR, 2009; PIKER y NUÑEZ, 2010; ROMERO, 2009).

En Ecuador, el 30 de septiembre de 2010, tras una huelga de "brazos caídos" por parte de las fuerzas policiales, Rafael Correa fue retenido en el medio de una protesta policial. Simultáneamente a estos hechos, un grupo de cuatrocientos soldados tomaron el control del aeropuerto Mariscal Sucre de Quito, la base aérea de Lacatunga, la Asamblea Nacional, el puerto y los aeropuertos de Guayaquil. Tras un lapso de más diez horas Correa logró ser liberado por un Grupo de Operaciones Especiales (GOE) del ejército y un Grupo de Intervención y Rescate (GIR) de la policía, impidiendo de esta manera la consumación del GE.

En los cuatro casos mencionados las fuerzas armadas intervinieron, considerando la particularidad del caso haitiano en donde soldados extranjeros participaron en la captura del presidente, aunque en ninguno de los casos se instauró una dictadura o una junta militar en el gobierno. Aunado a ello, en los casos ecuatoriano y venezolano, existió división dentro de las fuerzas armadas, permitiendo que pudieran ser revertidas las intentonas golpistas. Otro aspecto importante es que no se ejerció violencia abierta o masiva en contra de la población civil, o contra sectores políticos, y más bien se actuó de manera selectiva en la búsqueda de sus objetivos.

A diferencia de la tendencia dominante en el siglo XX, el ejército y la policía no han sido las únicas que han actuado para generar los golpes, un factor importante en los nuevos fenómenos es la participación activa de actores civiles, y en algunos casos, de la sociedad civil de manera masiva.

\section{b) Participación de la sociedad civil}

En la totalidad de los casos de GE en este nuevo siglo, han existido protestas sociales previas o posteriores a la realización del golpe o de la intentona de golpe. Este 
es un aspecto que consideramos importante en la definición y desarrollo de los GE del SXXI ya que las acciones de grupos u actores de la sociedad civil han tomado importancia en el desarrollo de estos fenómenos.

Por un lado, tenemos un conjunto de casos en los que la participación se dio previamente al GE, a través de protestas, movilizaciones y el ejercicio de fuerte presión política, este tipo de acciones las encontramos en los casos de Haití 2004, Bolivia 2008 y Brasil 2016. Para el caso de Haití existió una fuerte presión de grupos opositores que se movilizaron desde República Dominicana, aprovechando un contexto de dificultades económicas provocadas por el corte de fondos y préstamos extranjeros, hechos que terminaron por generar una importante presión política para Aristide (ÁLVAREZ, 2010).

En Bolivia desde mayo y hasta septiembre de 2008 se generó una fuerte movilización social liderada por los prefectos opositores de los departamentos de Santa Cruz, Tarija, Beni, Pando y Chuquisaca en contra del gobierno de Evo Morales, provocando un "paro cívico" que incluyó cortes de rutas internacionales hacia Argentina y Paraguay, toma y saqueo de edificios públicos, toma del aeropuerto de Tarija y amenazas de interrupción a las redes de suministro de gas hacia Argentina y Brasil. Producto de esta movilización se registraron enfrentamientos entre manifestantes y fuerzas de seguridad. Los hechos fueron denunciados por Morales como un intento de "golpe de Estado civil, cívico y prefectural" (ROJAS, 2008; LEMOINE, 2014; MALAMUD, 2008).

Para el caso de Brasil en 2016, los antecedentes de movilizaciones en contra del gobierno del PT se remontan hasta el año de 2013, cuando se fundaron tres movimientos "conservadores y radicalmente contrarios al PT": Revoltados On Line, el Movimiento Brasil Libre (MBL) y el Vem Para Rua (VPR) (BREDA, 2016). Estos tres movimientos que reunieron a grupos de clase media y alta mantuvieron un discurso en contra de la corrupción y organizaron, con ayuda de medios de comunicación, una serie de protestas en las ciudades más grandes de Brasil a lo largo de todo el año 2015. El día 13 de marzo de 2016 se realizó una multitudinaria manifestación política que logró reunir a más de 500.000 personas en apoyo al impeachment en contra de Dilma Roussef, quién finalmente fue destituida por el Congreso (BREDA, 2016; DARLING, 2015).

En estos tres casos podemos observar como la movilización de grupos de sociedad civil representa un elemento clave en la realización de los nuevos GE, al convertirse en un factor de presión política, ya que las manifestaciones de grupos 
civiles progresivamente generaron un clima de tensión e inestabilidad para justificar y legitimar (SOLER, 2015).

Por el otro lado, tenemos que la participación de la sociedad civil se puede expresar posteriormente al GE, esto es a través de la organización de protestas contra el acto e incluso en apoyo al gobernante depuesto. Este tipo de expresión la encontramos en Venezuela 2002, Haití 2004, Honduras 2009, Ecuador 2010, Paraguay 2012 y Brasil 2016. En el caso de Venezuela en 2002 tras la detención de Chávez se dio una gran movilización social alrededor del Palacio de Miraflores que coadyuvó a la vuelta al poder de Chávez en menos de 48 horas; caso parecido a lo sucedido en Ecuador donde tras la detención de Correa se registraron manifestaciones multitudinarias en apoyo al presidente. En el resto de los casos las protestas no influyeron en el desenlace del GE, aunque sí exhibían su carácter ilegítimo para una parte de la sociedad nacional.

Ambas expresiones, tanto las protestas a favor como en contra nos muestran un cambio importante en la realización del GE en la región, en tanto durante el siglo XX la presencia de Sociedad Civil no tuvo un rol importante.

\section{c) Intervención de instituciones judiciales}

Una característica que comparten tres casos es la intervención de poderes judiciales. En el caso hondureño la intervención judicial comenzó a gestarse desde enero de 2006 cuando se aprobó en el Congreso una ley "de participación ciudadana" en la que se permitía realizar consultas sobre asuntos nacionales. En 2009, a un año de finalizar su mandato, Zelaya impulsó la idea de colocar una cuarta urna en las elecciones de ese año para crear una nueva Constitución de la República. La oposición tomó este gesto como un intento de Zelaya por presentarse para un segundo mandato y debido a este reclamo se cambió el rotulo a una "encuesta de opinión pública” (LUQUE, 2016). Ante este hecho la Corte Suprema acusó a Zelaya de delitos como traición a la patria y abuso de autoridad, cargos que constitucionalmente implicaban la destitución del cargo. Aunque finalmente la destitución se realizó a través de la intervención militar, la postura del poder judicial generó condiciones que intentaron legitimar el GE (HUERTAS y CÁCERES, 2014; AGUILAR, 2009; PIKER y NUŃEZ, 2010, ROMERO, 2009).

Otro caso de intervención judicial lo tenemos en Paraguay 2012, cuando en el mes de mayo se registró un enfrentamiento entre campesinos y policías debido a una invasión de tierras en la provincia de Curuguaty. El enfrentamiento derivó en 17 muertes, 11 de campesinos y 6 policías. La particularidad del caso estuvo en que las 
tierras invadidas eran propiedad de Blas Riquelme, expresidente del Partido Colorado (LUQUE, 2016). Ante este hecho se provocaron diversas dimisiones de ministros y jefes policiales, sin embargo, el caso llegó a más, ya que se presentó en la Cámara de Diputados una propuesta para someter a juicio al presidente de la República bajo pretexto de que había actuado de manera "impropia, negligente e irresponsable", y que su gobierno estaba provocando la constante "confrontación y lucha de clases sociales” entre compatriotas (HUERTAS y CÁCERES, 2014). El proceso judicial en el Congreso tardó 48 horas en resolver, declarando culpable a Fernando Lugo y siendo destituido de su cargo. A este respecto el poder judicial tuvo una injerencia directa en el proceso ya que la defensa de Lugo reclamó acciones de inconstitucionalidad ante la Corte Suprema de Justicia con el fin de frenar el juicio político. El argumento de la defensa era que no se habían respetado los mínimos trámites procesales ya que el Congreso aprobó un reglamento para viabilizar y cerrar el proceso en menos de veinticuatro horas, por lo que los abogados de Lugo no tuvieron el tiempo necesario para preparar una defensa apropiada (YUSSEF, 2013).

El tercer caso relacionado a este aspecto lo tenemos en Brasil cuando el 2 de diciembre de 2015 comenzó un proceso de impeachment que culminó con la destitución de Dilma Rousseff el 31 de agosto de 2016. En este caso el poder judicial intervino desde julio de 2015 con la operación llamada "Lava Jato" en la que se culpaba a la presidenta de violar las leyes de responsabilidad fiscal, debido a que el gobierno retrasó una transferencia de casi mil millones de dólares al Banco de Brasil para el pago de un programa de crédito agrícola, ante la dilación el propio banco pago a los agricultores con sus propios recursos. Aunque el dinero posteriormente fue reintegrado, el acto se consideró como un "pedaleada” (LUQUE, 2016), un acto prohibido por la ley al considerar como un préstamo tomado por la presidencia de un banco estatal. El cargo por el cual Rousseff fue juzgada, fue maquillar el déficit presupuestal, aunque ella siempre negó haber realizado alguna acción ilegal, ya que mover dinero entre diferentes presupuestos era una práctica común que sus antecesores habían realizado. Cabe decir que la propia operación "Lava Jato" señaló a Eduardo Cunha (entonces presidente de la Cámara de Diputados) de recibir sobornos de hasta por 4,2 millones de dólares por parte de Petrobras, sin embargo, el propio Cunha aprobó el inicio del proceso de impeachment en contra de Roussef. De esta forma el poder judicial participó del proceso en contra de la presidenta Roussef (GALLAS, 2016; JIMÉNEZ, 2016; REMPIGIO, 2016). 
En los tres casos se puede observar como las decisiones tomadas por las Cortes generaron condiciones propicias para que el GE se llevará a cabo, avalando las acusaciones y cargos que se presentaron, además de permitir los procesos de impeachment aunque existieran irregularidades en los procesos. Cabe decir que un factor fundamental en los tres casos es que la oposición dominaba parte importante de los congresos y tenía una fuerte influencia en el poder judicial.

\section{d) Participación de instituciones parlamentarias}

En tres casos se presenta la participación de instituciones parlamentarias, o congresos: Honduras 2009, Paraguay 2012 y Brasil 2016. Para el caso de Honduras la intervención del Congreso antecede a la propia realización del GE a manos del ejército, ya que previamente había aprobado una ley para prohibir la celebración de una consulta popular impulsada por Zelaya. Posteriormente, una vez realizado el rapto y deportación del presidente, se reunió horas después y aceptó como válida una supuesta carta de renuncia de Zelaya, acto seguido se emitió un decreto oficial en el que se destituía y se le sustituía por el presidente del Congreso, Rigoberto Micheletti. De esta forma la detención y destitución cobró una presunta legalidad constitucional debido a las órdenes emitidas por la Suprema Corte de Justicia con el aval del Congreso (HUERTAS y CÁCERES, 2014, LUQUE 2016).

Debido a los llamados "Sucesos de Curuguaty", la destitución de Fernando Lugo en Paraguay se llevó a cabo a través de la Cámara de Diputados, ya que se emitió una moción de censura en contra de supuestas responsabilidades del gobernante. El juicio político fue iniciado por el diputado opositor Luis Gneiting el miércoles 20 de junio de 2012, acusándolo de responsabilidad política en los enfrentamientos entre campesinos y policías. La tarde del viernes 22 de junio, tras constituirse en tribunal del juicio, el Senado Paraguayo, presidido por Oviedo Matto, declaró culpable a Lugo, con 39 votos a favor y 4 en contra. Acto seguido se le tomó posesión del cargo al vicepresidente Federico Franco, del Partido Liberal Radical Auténtico (HUERTAS y CÁCERES, 2014). Como se ha señalado antes, el poder judicial tuvo responsabilidad en el proceso al omitir obligaciones del juicio en su debido proceso y rechazó todos los recursos presentados por la defensa del presidente.

El proceso de impeachment en contra de la presidenta Dilma Rousseff comenzó el 2 de diciembre de 2015, iniciado por Eduardo Cunha (entonces presidente de la Cámara de Diputados) por presuntas violaciones a las normas fiscales. Tras una larga sesión de 21 horas del Senado brasileño, el 12 de mayo de 2016, aprobó el proceso con 55 votos a favor y 22 votos en contra. Rousseff fue 
suspendida de su cargo por 180 días, mientras Michel Temer, vicepresidente y líder del Partido Democrático do Movimento Brasileiro (PMDB), quedo nombrado como presidente interino (GALLAS, 2016; JIMÉNEZ, 2016; REMPIGIO, 2016; LUQUE, 2016).

Estos tres casos hablan de una modalidad nueva en la realización de GE en la región, esto es la realización de Golpes Parlamentarios, protagonizados y realizados justamente por miembros de los poderes legislativos. La condición más importante para que este tipo de fenómenos puedan existir es que el presidente o presidenta en funciones no posea mayoría en el congreso, y a diferencia de los golpes militares, estos no usan la violencia abierta y más aún, se disfrazan detrás de procesos constitucionales legales.

\section{e) Mantenimiento de la "formalidad" democrática}

Tras el descrédito que ganaron los GE militares y las dictaduras militares en el siglo XX, y bajo la prédica de las transiciones democráticas en la región, los nuevos GE han buscado evadir su expresión militar más cruda para llevarse a cabo. En este sentido la intervención de instituciones judiciales y parlamentarias han representado una alternativa viable para mantener una "continuidad democrática" a pesar de la ruptura de los pactos constitucionales e institucionales. Así, podemos ver como en casos como los de Honduras 2009, Paraguay 2012 y Brasil 2016, se ha intentado hacer pasar el GE como una alternativa para resolver problemas de ingobernabilidad, de ineficiencia gubernativa, de impasse político, o incluso de fuertes confrontaciones entre grupos políticos. Un auxiliar importante en estos escenarios es la participación de grupos de la sociedad civil quienes mediante la presión o la manifestación abierta buscan dotar de legitimidad a estos fenómenos, aunque, en la mayoría de los casos, obedezcan abiertamente a las agendas políticas de determinados grupos de poder.

\section{f) Intervención de instituciones regionales y supranacionales}

En el contexto de los nuevos GE un nuevo elemento ha surgido, esto es la intervención de instituciones políticas supranacionales. A partir de los años noventa diversas instancias multilaterales regionales consideraron el compromiso con la democracia dentro de sus cláusulas: OEA, Mercosur, Unasur y CELAC, buscando a nivel regional mantener estabilidad.

En el caso de Venezuela 2002 el Grupo de Río se pronunció prontamente dado que estaban reunidos en Costa Rica celebrando la XVI Cumbre de Jefes de 
Estado y de Gobierno. El grupo condenó la irrupción del orden constitucional y se instó a la normalización democrática, de igual forma solicitaron al Secretario General de la OEA a llamar a una sesión especial del Consejo permanente a fin de adoptar una respuesta colectiva a la situación (PIGNATTA, 2014). En los sucesos de Honduras 2009 el Consejo permanente de la OEA emitió una resolución condenando el golpe y demandando la restitución de Zelaya en el poder. Ante el rechazo ante la solicitud de restitución se resolvió suspender a Honduras del ejercicio de sus derechos de participación en la OEA. En el caso de Ecuador 2010, ante la detención de Correa, la UNASUR celebró una reunión de emergencia en Buenos Aires, para condenar los hechos y coordinar una respuesta en común; de igual manera la OEA repudió los hechos. Ambas instituciones celebraron la liberación de Correa y la continuidad democrática (PIGNATTA, 2014). En el caso de Paraguay 2012, el Mercosur y la Unasur suspendieron a los representantes paraguayos de su participación en la siguiente cumbre, aplicando protocolos como los de Ushuaia y el Protocolo de Guyana, sin embargo, no lograron ninguna respuesta efectiva (YUSSEF, 2013; LUQUE 2016). En el caso de Bolivia en 2008 la UNASUR convocó a una cumbre presidencial el 15 de septiembre en Chile, en la que se acordó una posición unánime en la llamada Declaración de la Moneda, en el que se expresó un "pleno y decidido respaldo al Gobierno Constitucional del Presidente de la República de Bolivia Evo Morales, cuyo mandato fue ratificado por una amplia mayoría en el reciente referéndum", rechazaba la ruptura del orden institucional, el desmembramiento territorial, y una condena a la masacre de Pando.

A pesar de que en ningún caso la intervención de estas instituciones ha tenido un efecto directo vinculante, los pronunciamientos y posturas tomadas sí representan una novedad en la política regional.

\section{Conclusiones: hacia una definición del GE en el S XXI}

Visto de manera conjunta, el fenómeno de los GE en el SXXI ha sufrido algunos cambios importantes. Por un lado, tenemos que el principal cambio es la pérdida de preeminencia de la forma militar que tuvo durante en el siglo $\mathrm{XX}$, tanto en su ejecución como en la posterior instauración de un poder militar. Esto es presumiblemente, debido a la pérdida de legitimidad de la opción militar ante la hegemonía de la democracia como forma de hacer política en la región. En respuesta a la caída de su forma militar, el GE ha tenido un desplazamiento hacia la participación y acción de la sociedad civil, a través de la construcción de escenarios adecuados para la realización del golpe y su posterior legitimación. Para ello se ha 
apelado al discurso del GE como una forma de resolver el impasse político, de acabar con políticos ineptos y corruptos, y también de terminar con escenarios de confrontación política provocado por los gobernantes depuestos.

De igual forma, y a contrapelo de lo sucedido en el SXX, se ha legalizado el GE a través de la participación de instituciones judiciales o parlamentarias. Este es un aspecto muy delicado debido a que se rompen los equilibrios institucionales y la garantía jurídica del orden democrático, de manera que, aunque existan formalmente los límites institucionales nacionales o supranacionales no representan una garantía para evitar la ruptura del orden.

Este conjunto de elementos permite pensar acerca de la vigencia de las conceptualizaciones tradicionales sobre el GE, ya que sus nuevas expresiones han presentado nuevos elementos que no estaban previamente considerados, incluso al punto de llamar a este conjunto de nuevas experiencias como "neogolpismos".

Octavio Humberto Moreno Velador é Doutor em Sociologia, pela Benemérita Universidad Autónoma de Puebla. Professor Investigador da Facultad de Derecho y Ciencias Sociales da Benemérita Universidad Autónoma de Puebla, México. Membro do Sistema Nacional de Investigadores. E-mail: octaviohmoreno@ gmail.com.

- Carlos Alberto Figueroa Ibarra é Doutor em Sociologia, pela Universidad Nacional Autónoma de México Professor Investigador do Instituto de Ciencias Sociales y Humanidades da Benemérita Universidad Autónoma de Puebla, México. Membro Nivel II do Sistema Nacional de Investigadores. E-mail: carlosfigueroaibarra@, gmail.com.

\section{Referências}

AGUILAR, Carlos. ¿Cómo y porqué del golpe de Estado en Honduras?: la sinopsis de un proceso de pacificación y democratización fallido en la región. Revista Realidad, n. 121, p. 699-707, 2009. 
ÁLVAREZ, Alejandro. Movimientos sociales y procesos políticos en Haiti. In: GAVIA, Margarita Favela; GUILLÉN, Diana (Orgs.). América Latina. Los derechos y las prácticas ciudadanas a la luz de los movimientos populares. CLACSO: Buenos Aires, 2009, p. 245-271.

ANSALDI, Waldo. La democracia en América Latina, más cerca de la precariedad que de la fortaleza. Sociedad, n. 19, p. 23-54, 2001.

ANSALDI, Waldo. A mucho viento, poca vela. Las condiciones sociohistóricas de la democracia en América Latina. Una introducción. In: ANSALDI, Waldo. La democracia en América Latina, un barco a la deriva. Fondo de Cultura Económica, Buenos Aires, 2008, p. $29-52$.

BARBÉ, Carlos. "Golpe de Estado". In: BOBBIO, Norberto; MATTEUCCI, Nicola; PASQUINO, Gianfranco (Orgs.). Diccionario de política. México: Siglo XXI Editores, 2015, p. 723-726.

BREDA, Tadeu. Brasil, crónica de un impeachment anunciado. Los colores de un país escindido. Revista Nueva Sociedad, n. 263, p. 4-18, 2016. Disponible en: <http://nuso.org/media/articles/downloads/COY1_Breda_263.pdfs. Recuperado el: 16 oct. 2018.

DARLING, Victoria. La disputa por la calle. Cuando los sectores conservadores irrumpen en el espacio de la movilización social. Raigal. Revista Interdisciplinaria de Ciencias Sociales, n. 1, p. 23$34,2015$.

GALLAS, Daniel. Dilma Rousseff impeachment: How did it go wrong for her? BBC News. [en línea]. 2016. Disponible en: <http://www.bbc.com/news/world-latin-america-36028247>. Recuperado el: 22 sep. 2017.

GARGARELLA, Roberto. La "sala de máquinas" de las constituciones latinoamericanas. Entre lo viejo y lo nuevo. Revista Nueva Sociedad, n. 257, p. 96-106, 2015.

. Pensar la democracia, discutir sobre los derechos. Revista Nueva Sociedad, n. 267, p. 101$113,2017$.

GARRETÓN, Manuel. Revisando las transiciones democráticas en América Latina. Revista Nueva Sociedad, n. 148, p. 20-29, 1997.

GRAMSCI, Antonio. Cuadernos de la cárcel. Tomo 2, México. Biblioteca ERA. Benemérita Universidad Autónoma de Puebla. 1999.

GUERRERO, Modesto. Memoria del golpe de Estado en América Latina durante el siglo XX. Red Voltaire, Sección Archivos, 2006. Disponible en: <http://www.voltairenet.org/article137304.html>. Recuperado el: 25 jun. 2018.

HUERTAS, Omar; CÁCERES, Victor. Los golpes de Estado constitucionales en Latinoamérica: una amenaza emergente para el principio democrático. Justicia Juris, v. 10, n. 2, p. 28-35, 2014. Disponible en: <http://www.scielo.org.co/scielo.php?script=sci_arttext\&pid=S169285712014000200004. Recuperado el: 30 mayo 2018.

JIMÉNEZ, Antonio. El Senado abre el proceso de 'impeachment' contra Rousseff y la aparta del poder. El País. [en línea]. 2016. Disponible en: <https://elpais.com/internacional/2016/05/12/actualidad/1463015345_730062.html>. Recuperado el: 22 sep. 2017.

LECHNER, Norbert. La crisis del Estado en América Latina. Venezuela. El Cid Editor. 1977.

LEMOINE, Maurice. La era de los golpes de estado suaves en América Latina. Asociación Mémoire des luttes [en línea]. 2014. Disponible en: <http://www.medelu.org/La-era-de-los-golpes-deEstado>. Recuperado el: 12 mayo 2018. 
LUQUE, Pedro. Las claves del neogolpismo. Diario La voz Argentina. 23 de abril de 2016. Disponible en: <http://www.lavoz.com.ar/mundo/las-claves-del-neogolpismo>. Recuperado el: 15 jun. 2018.

LYNN, Terry. Dilemmas of Democratization in Latin America. Compartive Politics, v. 23, n. 1, p. 121, 1990.

MALAMUD, Carlos. La cumbre de Unasur en Santiago de Chile y el conflict en Bolivia. Boletín Elcano, n. 121, p. 9, 2008. Disponible en: <http://biblioteca.ribei.org/1403/>. Recuperado el: 25 jul. 2018.

MEYSSAN, Thierry. Estados Unidos y Francia derrocan a Aristide [en línea]. Golpe de Estado en Haití. Voltairenet.org, 2004. Disponible en: <http://www.voltairenet.org/article120678.html>. Recuperado el: 03 abr. 2018.

MORLINO, Leonardo. Democracias y democratizaciones. México: Centro de Estudios de Política Comparada, 2005.

NOHLEN, Dieter. Diccionario de Ciencia Política. Teorías, métodos y conceptos. Editorial Porrua. El Colegio de Veracruz, 2006.

O’DONNELL, Guillermo; SCHMITTER, Philippe; WHITEHEAD, Lawrence. Transiciones desde un gobierno autoritario. América Latina. Barcelona: Ediciones Paidós, Barcelona, v. 2, 1994.

PASQUINO, Gianfranco. "Revolución”. In: BOBBIO, Norberto; MATEUCCI, Nicola (Orgs.). Diccionario de Política L-Z. México: Siglo Veintiuno Editores, 1982.

PÉREZ- LIÑÁN, Aníbal; MAINWARING, Scott. La supervivencia de la democracia en América Latina (1945-2005). América Latina Hoy, n. 68, p. 139-168, 2014.

PIGNATTA, María. Multilateralismo y compromiso con la democracia en América Latina: casos, actores y debates. Explorando su devenir en el siglo XXI. V Encuentro del CERPI y III Jornadas del CENSUD. Democracia y relaciones internacionales en América Latina, Universidad Nacional de la Plata, 2014.

PIKER, Cristina; NÚNEZZ, Omar. Cuatro hipótesis y un corolario en torno al golpe de Estado en Honduras. OSAL, v. 11, n. 28, p. 123-124, 2010.

POLITICUS, Orheva. Diccionario de política. Buenos Aires: Valleta Ediciones, 2001.

PORTANTIERO, Juan. Los usos de Gramsci. México. Folios Ediciones. 1981.

PRZEWORSKI, Adam. Qué esperar de la democracia. Límites y posibilidades del autogobierno. Argentina. Siglo Veintiuno Editores, 2010.

RAMÍREZ, Rafael. Breve diccionario de la política. Espanã: Ediciones Mensajero, p. 106, 1997.

REMPIGIO, Marcelo. ¿Qué es la operación Lava Jato? La Nación. [en línea]. 2016. Disponible en: <http://www.nacion.com/mundo/latinoamerica/operacion-Lava-Jato_0_1603239762.html>.

Recuperado el: 22 sep. 2017.

ROJAS, Rosa (Corresponsal). En Bolivia, en marcha un golpe de Estado atípico, denuncia Evo Morales. La Jornada, v. 24, n. 8646, 2008. Disponible en: <http://www.jornada.unam.mx/2008/09/11/index.php?section=mundo\&article=036n 1 mun $>$.

Recuperado el: 25 jun. 2018.

ROMERO, Ramón. Por la democracia y contra el golpe. Un análisis independiente. Centro de Documentación de Honduras, 2009. Disponible en: <http://www.cedoh.org/documentacion/articulos/files/DEMOCRACIA\%20CONTRA\%20EL\%20 GOLPE.pdf>. Recuperado el: 02 jun. 2018. 
172

Octavio Humberto Moreno Velador e Carlos Alberto Figueroa Ibarra

ROUQUIÉ, Alain. A la sombra de las dictaduras. La democracia en América Latina, México: Fondo de Cultura Económica, 2011. . El estado militar en América Latina, México: Siglo XXI, 1984.

RUÍZ, Pablo. Cronología: Golpes de Estado en América Latina. Telesur, 5 de septiembre de 2016. Disponible en: <https://www.telesurtv.net/opinion/Cronologia-Golpe-de-Estado-en-AmericaLatina-20160905-0020.html>. Recuperado el: 29 jun. 2018.

SERRA, Andrés. Diccionario de Ciencias Política. México: Facultad de Derecho/UNAM-Fondo de Cultura Económica, p. 542, 1998.

SMITH, Peter. La democracia en América Latina, Madrid: Instituto de Estudios LatinoamericanosUniversidad de Alcalá, 2009.

SMITH, Peter. Los ciclos de democracia electoral en América Latina 1900-2000. Política y Gobierno, v. 1I, n. 2, p. 189-228, 2004.

SOLER, Lorena. Golpes de Estado en el siglo XXI. Un ejercicio comparado Haití (2004), Honduras (2009) y Paraguay (2012). Cuadernos Prolam, v. 14, n. 26, p. 77-89, 2004. Disponible en: <https:/www.revistas.usp.br/prolam/article/view/103317>. Recuperado el: 02 jun. 2018.

VICTORIANO, Felipe. Estados, golpes de Estado y militarización en América Latina. Una reflexión histórico política. Argumentos, v. 23, n. 64, p. 175-193, 2014.

WHITEHEAD, Laurence. Democratización. Teoría y experiencia. México: Fondo de Cultura Económica, 2011.

YUSSEF, Nabih. Neogolpismo: el caso paraguayo. Boletín Informativo del CENSUD, n. 41. 2013. Disponible en: <http://sedici.unlp.edu.ar/handle/10915/39912>. Recuperado el: 02 jun. 2018.

Texto recebido em 14 de junho de 2018. Aprovado em 11 de fevereiro de 2019. 